\title{
Estimating the photosynthetically active radiation under clear skies by means of a new approach
}

\author{
W. Wandji Nyamsi, B. Espinar, P. Blanc, and L. Wald \\ MINES ParisTech, PSL Research University, O. I. E. - Centre Observation, Impacts, Energy, \\ Sophia Antipolis CEDEX, France \\ Correspondence to: W. Wandji Nyamsi (william.wandji@mines-paristech.fr)
}

Received: 2 December 2014 - Accepted: 26 January 2015 - Published: 18 February 2015

\begin{abstract}
The $k$-distribution method and the correlated- $k$ approximation of Kato et al. (1999) is a computationally efficient approach originally designed for calculations of the broadband solar radiation by dividing the solar spectrum in 32 specific spectral bands from 240 to $4606 \mathrm{~nm}$. This paper describes a technique for an accurate assessment of the photosynthetically active radiation (PAR) from 400 to $700 \mathrm{~nm}$ at ground level, under clear-sky conditions using twelve of these spectral bands. It is validated against detailed spectral calculations of the PAR made by the radiative transfer model libRadtran. For the direct and global PAR irradiance, the

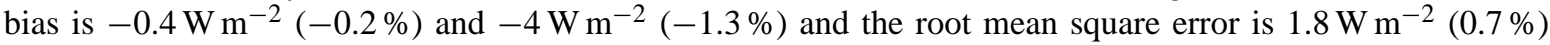
and $4.5 \mathrm{~W} \mathrm{~m}^{-2}(1.5 \%)$. For the direct and global Photosynthetic Photon Flux Density, the biases are of about $+10.3 \mu \mathrm{mol} \mathrm{m}^{-2} \mathrm{~s}^{-1}(+0.8 \%)$ and $1.9 \mu \mathrm{mol} \mathrm{m}^{-2} \mathrm{~s}^{-1}(-0.1 \%)$ respectively, and the root mean square error is $11.4 \mu \mathrm{mol} \mathrm{m}{ }^{-2} \mathrm{~s}^{-1}(0.9 \%)$ and $4.0 \mu \mathrm{mol} \mathrm{m}^{-2} \mathrm{~s}^{-1}(0.3 \%)$. The correlation coefficient is greater than 0.99 . This technique provides much better results than two state-of-the-art empirical methods computing the daily mean of PAR from the daily mean of broadband irradiance.
\end{abstract}

\section{Introduction}

Photosynthetically active radiation, abbreviated in PAR, is the solar radiation in the range $[400,700] \mathrm{nm}$ that can be used by organisms via the process of photosynthesis. PAR is defined as the incident power per unit surface for this spectral interval and may be expressed in $\mathrm{W} \mathrm{m}^{-2}$. PAR is also a measure of the photosynthetic photon flux density, abbreviated in PPFD and expressed in $\mu \mathrm{mol} \mathrm{m} \mathrm{m}^{-2} \mathrm{~s}^{-1}$, and is defined as the number of the incident photons per unit time per unit surface. Both units are linked by the widely used approximation $1 \mathrm{~W} \mathrm{~m}^{-2} \approx 4.57 \mu \mathrm{mol} \mathrm{m}^{-2} \mathrm{~s}^{-1}$ (McCree, 1972). PAR is a portion of the total, also known as broadband, solar irradiance. Whatever the spectral interval, the solar radiation available at ground level on a horizontal plane is called the global radiation. The global is the sum of the direct component that comes from the direction of the sun and the diffuse component that comes from the rest of the sky vault. Let note respectively $G, P_{\mathrm{G}}$ and $Q_{\mathrm{P}}$, the global broadband irradiance, the global PAR irradiance, and the global PPFD at ground level.
In situ measurements of PAR are rare in space and time. This scarcity leads researchers and practitioners to calculate PAR from the global broadband solar irradiance by empirical means. For example, Udo and Aro (1999) proposed a ratio of 2.079 between the daily mean of $G$ and the daily mean of $Q_{\mathrm{P}}$ :

$Q_{\mathrm{P}}=2.079 G$

where the constant 2.079 is in $\mu \mathrm{mol} \mathrm{J}^{-1}$. Jacovides et al. (2004) suggested a ratio of 1.919. These authors acknowledge that the actual ratio depends on the sky conditions and atmospheric properties.

Other approaches to PAR assessment and more generally to assessment of the solar radiation in any spectral interval are atmospheric radiative transfer models (RTM). Besides the difficulty in knowing all inputs requested by RTMs, their main disadvantage is the computational load because many spectral calculations must be performed. Several methods have been proposed to reduce the number of calculations. Among them, are the $k$-distribution method and the correlated- $k$ approximation proposed by Kato et al. (1999) 
Table 1. KB covering and close to PAR spectral interval, selected sub-intervals $\delta \lambda_{i}$, slopes and intercepts of the affine functions between the clearness indices in KB and sub-intervals $\delta \lambda_{i}$ obtained from libRadtran simulations.

\begin{tabular}{|c|c|c|c|c|c|c|}
\hline \multirow[t]{2}{*}{ KB } & \multirow{2}{*}{$\begin{array}{c}\text { Interval } \Delta \lambda, \\
\qquad \mathrm{nm}\end{array}$} & \multirow{2}{*}{$\begin{array}{l}\text { Sub-interval } \delta \lambda \text {, } \\
\mathrm{nm}(\# i)\end{array}$} & \multicolumn{2}{|c|}{ Global } & \multicolumn{2}{|c|}{ Direct normal } \\
\hline & & & Slope $a_{i}$ & Intercept $b_{i}$ & Slope $c_{i}$ & Intercept $d_{i}$ \\
\hline 6 & $363-408$ & 385-386 (\#1) & 0.9987 & -0.0023 & 1.0030 & -0.0032 \\
\hline 7 & $408-452$ & 430-431 (\#2) & 1.0026 & -0.0004 & 0.9995 & 0.0013 \\
\hline 8 & $452-518$ & 484-485 (\#3) & 1.0034 & 0.0005 & 0.9979 & 0.0000 \\
\hline 9 & $518-540$ & 528-529 (\#4) & 0.9998 & -0.0005 & 1.0008 & -0.0013 \\
\hline 10 & $540-550$ & 545-546 (\#5) & 1.0001 & 0.0003 & 1.0003 & -0.0003 \\
\hline \multirow[t]{2}{*}{11} & $550-567$ & 558-559 (\#6) & 1.0004 & 0.0004 & 0.9997 & 0.0012 \\
\hline & & 569-570 (\#7) & 0.9960 & -0.0119 & 1.0024 & -0.0100 \\
\hline \multirow[t]{3}{*}{12} & $567-605$ & 586-587 (\#8) & 1.0123 & 0.0064 & 0.9929 & 0.0267 \\
\hline & & 589-590 (\#9) & 0.9568 & -0.0109 & 0.9804 & -0.0434 \\
\hline & & 602-603 (\#10) & 1.0150 & 0.0167 & 1.0051 & 0.0212 \\
\hline \multirow[t]{2}{*}{13} & $605-625$ & 615-616 (\#11) & 1.0004 & 0.0009 & 0.9977 & 0.0033 \\
\hline & & $625-626(\# 12)$ & 1.0104 & -0.0174 & 1.0622 & -0.0551 \\
\hline \multirow[t]{2}{*}{14} & $625-667$ & 644-645 (\#13) & 1.0072 & 0.0029 & 0.9960 & 0.0154 \\
\hline & & 656-657 (\#14) & 0.9915 & 0.0068 & 0.9698 & 0.0205 \\
\hline \multirow[t]{2}{*}{15} & $667-684$ & 675-676 (\#15) & 1.0006 & 0.0007 & 0.9978 & 0.0036 \\
\hline & & 685-686 (\#16) & 1.0473 & 0.0212 & 0.9681 & 0.1036 \\
\hline \multirow[t]{2}{*}{16} & 684-704 & 687-688 (\#17) & 0.9602 & -0.0130 & 1.0041 & -0.0531 \\
\hline & & 694-695 (\#18) & 0.9828 & -0.0153 & 1.0323 & -0.0642 \\
\hline 17 & 704-743 & 715-716 (\#19) & 1.0262 & 0.0121 & 0.9771 & 0.0596 \\
\hline
\end{tabular}

whose approach is implemented in several RTMs. This approach was originally designed as a very efficient way to speed up computations of $G$ and its direct component by using 32 specific spectral intervals across the solar spectrum from 240 to $4606 \mathrm{~nm}$. Hereafter, these spectral intervals are abbreviated in KB. This article deals with the assessment of the PAR - irradiance and PPFD - using the irradiance of each $\mathrm{KB}$ covering the PAR spectral range in clear sky conditions.

\section{Problem statement}

The global PAR irradiance $P_{\mathrm{G}}$ is mathematically defined as:

$P_{\mathrm{G}}=\int_{400}^{700} G_{\lambda} d \lambda$

where $G_{\lambda}$ is the global spectral irradiance, $\lambda$ the wavelength and the integration is made between 400 and $700 \mathrm{~nm}$. The global PPFD $Q_{\mathrm{P}}$ is similarly defined as:

$Q_{\mathrm{P}}=\frac{1}{h c} \int_{400}^{700} G_{\lambda} \lambda d \lambda$

where $h$ is the Planck's constant and $c$ the velocity of light.

The direct normal irradiance is the irradiance received on a plane always facing the sun rays with a normal incidence. Let note respectively $B, P_{\mathrm{B}}$, and $Q_{\mathrm{PB}}$, the direct normal broadband irradiance, the direct normal PAR irradiance, and the direct normal PPFD:

$$
\begin{aligned}
& P_{\mathrm{B}}=\int_{400}^{700} B_{\lambda} d \lambda \\
& Q_{\mathrm{PB}}=\frac{1}{h c} \int_{400}^{700} B_{\lambda} \lambda d \lambda
\end{aligned}
$$

where $B_{\lambda}$ is the direct normal spectral irradiance.

The integral may be replaced by a Riemann sum using very narrow spectral intervals or bands, hereafter abbreviated NB. Here, we chose $\delta \lambda=1 \mathrm{~nm}$, assuming that the optical properties of the atmosphere do not change over $1 \mathrm{~nm}$. If $\lambda_{i}$ denotes now the center wavelength of each NB of width $\delta \lambda$, it comes:

$$
\begin{aligned}
P_{\mathrm{G}} & =\sum_{i=1}^{300} G_{\delta \lambda i} \\
Q_{\mathrm{P}} & =\frac{1}{h c} \sum_{i=1}^{300} G_{\delta \lambda i} \lambda_{i} .
\end{aligned}
$$

Similar equations hold for $P_{\mathrm{B}}$ and $Q_{\mathrm{PB}}$.

The PAR spectral band $[400,700] \mathrm{nm}$ is covered by $11 \mathrm{~KB}$, from \#6 [363, 408] nm to \#16 [684, 704] nm (Table 1). Wandji Nyamsi et al. (2014) demonstrated that as a whole the approach of Kato et al. (1999) offer accurate estimates of the spectral irradiance in most of the $32 \mathrm{~KB}$ when compared to detailed spectral calculations in clear sky and cloudy conditions, and especially for the KB \#6 to 16 . It follows that the 
PAR may be computed by a Riemann sum based on $11 \mathrm{~KB}$ instead of $300 \mathrm{NBs}$. KB \#6 and \#16 are partly outside the PAR range. One solution is a weighted sum based on the overlap between $\mathrm{KB}_{j}$ and the PAR interval. The weight $w_{j}$ of $\mathrm{KB}_{j}$ may be defined as follows:

$w_{j}=1$, if $j$ is not 6 or 16

$w_{6}=(408-400) /(408-363)=0.1778$

$w_{16}=(700-684) /(704-684)=0.80$

and

$P_{\mathrm{G}}=\sum_{j=6}^{16} G_{\mathrm{KB}_{j}} w_{j}$

$Q_{\mathrm{P}}=\frac{1}{h c} \sum_{j=6}^{16} G_{\mathrm{KB}_{j}} w_{j} \lambda_{\mathrm{KB}_{j}}$

where $G_{\mathrm{KB}_{j}}$ is the global irradiance for $\mathrm{KB}_{j}$ and $\lambda_{\mathrm{KB}_{j}}$ the center wavelength of $\mathrm{KB}_{j}$. Similar equations hold for $P_{\mathrm{B}}$ and $Q_{\mathrm{PB}}$. However, Wandji Nyamsi et al. (2014) reported a relative root mean square error less than $2 \%$ between detailed spectral calculations and the approach by Kato et al. (1999) for each $\mathrm{KB}$, from \#6 to \#16. Though small this error may be decreased for the PAR by the technique proposed in this article.

\section{Description of the technique}

Actually, the bandwidth in several KB is larger than $30 \mathrm{~nm}$ and may be considered large for estimating PAR in an accurate manner. The concept underlying the proposed technique is to determine several narrower spectral bands NB whose transmissivities are correlated to those of the $\mathrm{KB}$ and then use these transmissivities in a linear interpolation process to compute the PAR. This technique is elaborated and validated by the means of the RTM libRadtran (Mayer and Kylling, 2005).

The clearness index $\mathrm{KT}_{i}$ and the direct clearness index $\mathrm{KT}_{\mathrm{B} i}$ - also called atmospheric transmissivity and direct atmospheric transmissivity - are defined as follows:

$$
\begin{aligned}
\mathrm{KT}_{i} & =\frac{G_{\delta \lambda i}}{E_{o_{i}} \cos \left(\theta_{\mathrm{s}}\right)} \\
\mathrm{KT}_{\mathrm{B} i} & =\frac{B_{\delta \lambda i}}{E_{o_{i}}}
\end{aligned}
$$

where $\theta_{\mathrm{S}}$ is the solar zenithal angle; $E_{O_{i}}$ is the irradiance at the top of atmosphere on a plane normal to the sun rays for the $i$ th NB. Several solar spectra $E_{O_{i}}$ have been published. That of Gueymard (2004) is available in libRadtran and has been used here. By introducing the clearness index in Eqs. (6) and (7), it comes:
Table 2. Ranges and distributions of values taken by the solar zenith angle, the ground albedo and the 7 variables describing the clear

\begin{tabular}{|c|c|}
\hline Variable & Value \\
\hline $\begin{array}{l}\text { - Solar zenith angle } \theta_{\mathrm{S}} \\
\text { - Ground albedo } \rho g \\
\text { - Total column content of ozone }\end{array}$ & $\begin{array}{l}\text { - Uniform between } 0 \text { and } 89 \text { (degree) } \\
\text { - Uniform between } 0 \text { and } 0.9 \\
\text { - Ozone content is: } 300 \times \beta+200 \text {, in } \\
\text { Dobson unit. Beta distribution, with } \\
A \text { parameter }=2 \text {, and } B \text { parameter }=2 \text {, } \\
\text { to compute } \beta\end{array}$ \\
\hline $\begin{array}{l}\text { - Total column content of water } \\
\text { vapor }\end{array}$ & - Uniform between 0 and $70\left(\mathrm{~kg} \mathrm{~m}^{-2}\right)$ \\
\hline $\begin{array}{l}\text { - Elevation of the ground above } \\
\text { mean sea level }\end{array}$ & $\begin{array}{l}\text { - Equiprobable in the set: }\{0,1,2,3\} \\
(\mathrm{km})\end{array}$ \\
\hline - Atmospheric profiles (Air Force & - Equiprobable in the set: \\
\hline $\begin{array}{l}\text { Geophysics Laboratory } \\
\text { standards) }\end{array}$ & $\begin{array}{l}\text { \{"Midlatitude Summer", } \\
\text { "Midlatitude Winter", "Subarctic } \\
\text { Summer", "Subarctic Winter", } \\
\text { "Tropical”, "US Standard"\} }\end{array}$ \\
\hline - Aerosol optical depth at $550 \mathrm{~nm}$ & $\begin{array}{l}\text { - Gamma distribution, with shape } \\
\text { parameter }=2, \text { and scale } \\
\text { parameter }=0.13\end{array}$ \\
\hline - Angström coefficient & $\begin{array}{l}\text { - Normal distribution, with mean }=1.3 \\
\text { and standard-deviation }=0.5\end{array}$ \\
\hline - Aerosol type & $\begin{array}{l}\text { - Equiprobable in the set: \{“urban”, } \\
\text { "rural", "maritime", "tropospheric", } \\
\text { "desert", "continental", "Antarctic”\} }\end{array}$ \\
\hline
\end{tabular}
atmosphere.

$P_{\mathrm{G}}=\cos \left(\theta_{\mathrm{S}}\right) \sum_{i=1}^{300} E_{o_{i}} \mathrm{KT}_{i}$

$Q_{\mathrm{P}}=\frac{\cos \left(\theta_{\mathrm{S}}\right)}{h c} \sum_{i=1}^{300} E_{o_{i}} \mathrm{KT}_{i} \lambda_{i}$

Similar equations hold for $P_{\mathrm{B}}$ and $Q_{\mathrm{PB}}$. A set of 60000 clear sky atmospheric states is built by the mean of Monte-Carlo technique that will be input to libRadtran. Table 2 reports the nine input variables selected with seven of them describing the clear sky atmosphere: $\theta_{\mathrm{s}}$, ground albedo, total column content of water vapor and ozone, the vertical profile of temperature, pressure, density, and volume mixing ratio for gases as a function of altitude, the aerosol optical depth at $550 \mathrm{~nm}$, Angström coefficient, and aerosol type, and the elevation of the ground above sea level. The random selection of inputs takes into account the modelled marginal distribution established from observation proposed by Lefevre et al. (2013) and Oumbe et al. (2011). More precisely, the uniform distribution is chosen as a model for marginal probability for all parameters except aerosol optical thickness, Angstrom coefficient, and total column content of ozone. The chi-square law for aerosol optical thickness, the normal law for the Angstrom coefficient, and the beta law for total column content of ozone have been selected. The selection of these parametric probability density functions and their corresponding parameters have been empirically determined from the analyses of the observations made in the AERONET network for aerosol properties and from meteorological satellite-based ozone products (Lefevre et al., 2013). 
Several plots were made superimposing $\mathrm{KT}_{\mathrm{KB}}$ and $\mathrm{KT}_{i}$ obtained every $\mathrm{nm}$ for the interval $[363,743] \mathrm{nm}$. A visual inspection of the differences between $\mathrm{KT}_{\mathrm{KB}}$ and $\mathrm{KT}_{i}$ helps in establishing a set of selected NB, taking into account that the number of these sub-intervals should be as small as possible but still retaining a high accuracy when using a linear interpolation between the sub-intervals to compute the PAR, as explained later. Table 1 reports the $12 \mathrm{~KB}$ and the 19 subintervals NB. The KB \#17 is necessary to obtain NBs enclosing the PAR interval. All KBs contain one NB, except $\mathrm{KB} \# 12,14$ and 16, where 4, 3 and $3 \mathrm{NBs}$ were found respectively. These bands exhibit strong variations of $\mathrm{KT}_{i}$ that cannot be accounted for with a single NB.

In each selected NB, an affine function is determined by least-square fitting technique:

$\mathrm{KT}_{i}=a_{i} \mathrm{KT}_{\mathrm{KB}_{j}}+b_{i}$

$\mathrm{KT}_{\mathrm{B} i}=c_{i} \mathrm{KT}_{\mathrm{BKB}_{j}}+d_{i}$.

Table 1 also reports the slope and intercept for the global and direct clearness indices for each selected NB. This set of affine functions is established once for all. For any atmospheric state, given the twelve values of $\mathrm{KT}_{\mathrm{KB}_{j}}$ and $\mathrm{KT}_{\mathrm{BKB}_{j}}$, the nineteen $\mathrm{KT}_{i}$ and $\mathrm{KT}_{\mathrm{B} i}$ are computed for each corresponding NB using the affine functions. Then, $\mathrm{KT}$ and $\mathrm{KT}_{\mathrm{B}}$ are computed for each $\mathrm{nm}$ between 400 and $700 \mathrm{~nm}$ using a linear interpolation with $\mathrm{KT}_{i}$ and $\mathrm{KT}_{\mathrm{B} i}$ as nodes. Finally, Eqs. (12)-(13) provide $P_{\mathrm{G}}$ and $Q_{\mathrm{P}}$. A similar process yields the direct normal PAR: $P_{\mathrm{B}}$ and $Q_{\mathrm{PB}}$.

\section{Numerical validation}

A comparison of the results of the proposed technique against the results from the detailed spectral calculations made by libRadtran considered as a reference is performed to assess the performances of the proposed technique for $P_{\mathrm{G}}$, $Q_{\mathrm{P}}, P_{\mathrm{B}}$ and $Q_{\mathrm{PB}}$. Then, these performances are compared to those obtained for $Q_{\mathrm{P}}$ by the methods proposed by Jacovides et al. (2004), Udo and Aro (1999) and the weighted sum (Eq. 9). Another sample of 15000 atmospheric states has been constructed and used for validation.

\subsection{Performance of the proposed technique}

Deviations: estimates minus reference, are computed for each state of the validation sample for $P_{\mathrm{G}}, Q_{\mathrm{P}}, P_{\mathrm{B}}$ and $Q_{\mathrm{PB}}$. They are synthesized by the bias, the root mean square error (RMSE) and the correlation coefficient. The relative bias and RMSE are computed relative to the mean value of the reference. Figure 1 exhibits these statistical parameters for the global and direct normal PAR irradiance and PPFD. For the direct component, the bias for PAR irradiance, respectively PPFD, is $-0.4 \mathrm{~W} \mathrm{~m}^{-2}$, i.e. $-0.2 \%$ in relative value, and $+10.3 \mu \mathrm{mol} \mathrm{m} \mathrm{s}^{-2} \mathrm{~s}^{-1}$, i.e. $+0.8 \%$ in relative value. The RMSE is respectively $1.8 \mathrm{~W} \mathrm{~m}^{-2}(0.7 \%)$ and (a)
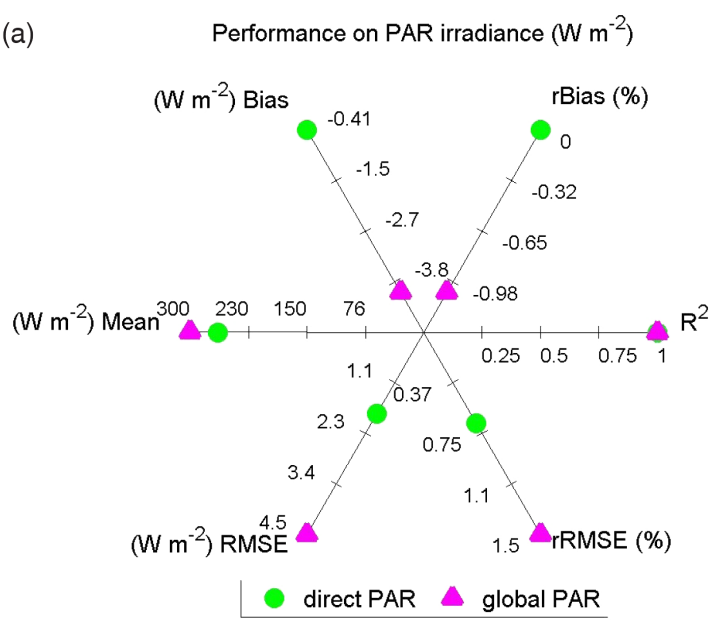

(b) Performance on photosynthetic photon flux density $\left(\mu \mathrm{mol} \mathrm{m} \mathrm{m}^{-2} \mathrm{~s}^{-1}\right)$

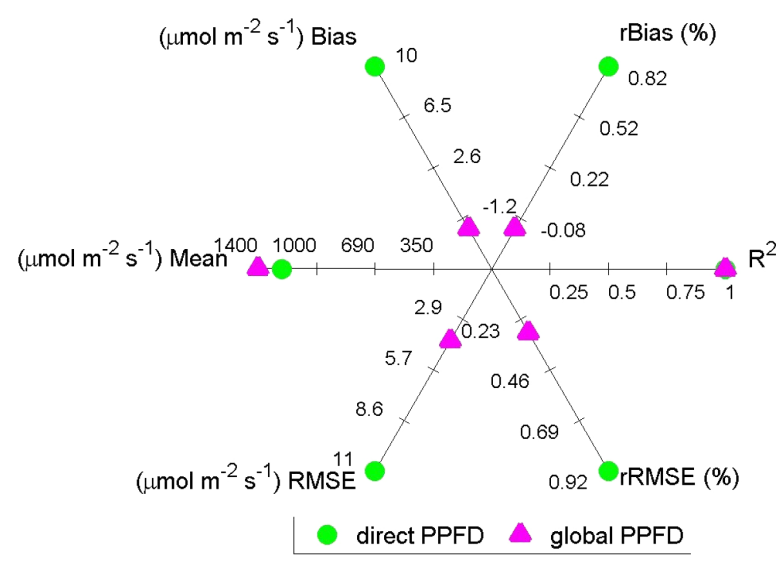

Figure 1. Synthesis of the performance of the proposed technique.

$11.4 \mu \mathrm{mol} \mathrm{m} \mathrm{m}^{-2} \mathrm{~s}^{-1}(0.9 \%)$. For the global, the bias for PAR irradiance, respectively PPFD, is $-4.0 \mathrm{~W} \mathrm{~m}^{-2}$, i.e. $-1.3 \%$ in relative value, and $1.9 \mu \mathrm{mol} \mathrm{m}{ }^{-2} \mathrm{~s}^{-1}$, i.e. $-0.1 \%$ in relative value. The RMSE is respectively $4.5 \mathrm{~W} \mathrm{~m}^{-2}(1.5 \%)$ and $4.0 \mu \mathrm{mol} \mathrm{m} \mathrm{m}^{-2} \mathrm{~s}^{-1}(0.3 \%)$. The coefficient of determination $R^{2}$ is greater than 0.99 . These figures prove the good level of performance of the proposed technique.

\subsection{Comparison with other methods}

Figure 2 exhibits the statistical indicators for $Q_{\mathrm{P}}$ obtained by the methods of Jacovides et al. (2004), Udo and Aro (1999), weighted sum and the proposed technique. The method of Jacovides et al. underestimates the PAR by $-7.4 \%$; the relative RMSE is $9.6 \%$. The method of Udo and Aro shows better results with a relative bias of $0.3 \%$ and a relative RMSE of $4.7 \%$. The weighted sum exhibits very low relative bias: $-0.2 \%$, and relative RMSE: $0.3 \%$. The proposed technique shows also a very good agreement with a relative bias of 


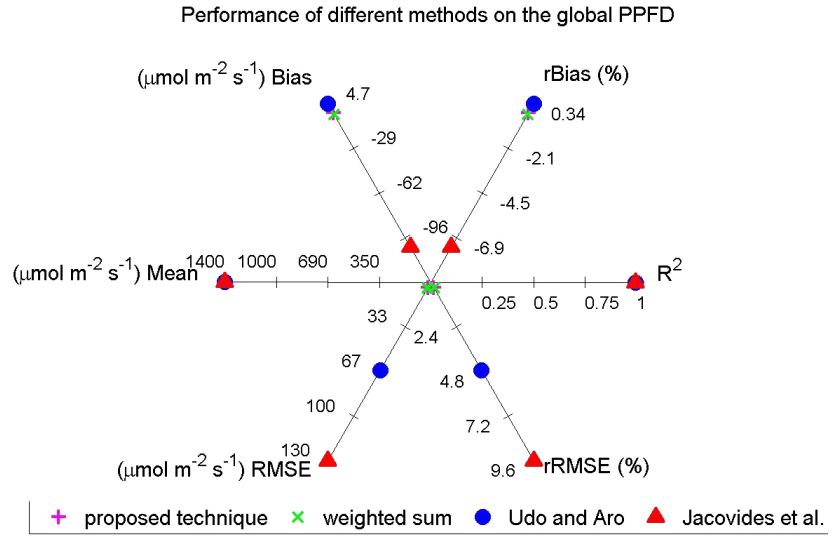

Figure 2. Performance of different methods: Jacovides et al. (2004); Udo and Aro (1999), weighted sum and the proposed technique.

$-0.1 \%$ and relative RMSE of $0.3 \%$ and offers the same results than the weighted sum.

There are two causes for this similarity. The first cause is that all KB contain one $\delta \lambda_{i}$, except KB \#12, 14 and 16. For these bands, variations of $\mathrm{KT}_{i}$ with $\lambda_{i}$ are very small. If it were the case for all KB, from \#6 to \#17, the proposed technique and the weighted sum would agree and provide similar results. But small discrepancies happen between both techniques due to the bands KB \#12, 14 and 16, which are subdivided by respectively 4,3 and $3 \delta \lambda_{i}$. However, the contribution of these bands to the PAR outside the atmosphere is only $25 \%$ approximately. As a consequence, these small discrepancies have a small influence on the final result. Both the weighted sum and the proposed technique exhibit better performances than the empirical method because both take into account the actual atmospheric effects by the means of the Kato et al. approach.

\section{Conclusions}

The $k$-distribution method and the correlated- $k$ approximation of Kato et al. (1999) is a computationally efficient approach originally designed for calculations of the broadband solar radiation at ground level by dividing the solar spectrum in 32 specific spectral bands from 240 to $4606 \mathrm{~nm}$. This paper describes a technique for an accurate assessment of the PAR under clear-sky conditions using the irradiance estimated in twelve of these spectral bands. The validation against numerical simulation exhibits very good performances. For the direct and global PAR irradiance, the bias is $-0.4 \mathrm{~W} \mathrm{~m}^{-2}(-0.2 \%)$ and $-4 \mathrm{~W} \mathrm{~m}^{-2}(-1.3 \%)$ and the RMSE is $1.8 \mathrm{~W} \mathrm{~m}^{-2}(0.7 \%)$ and $4.5 \mathrm{~W} \mathrm{~m}^{-2}(1.5 \%)$. For the direct and global PPFD, the bias of is $+10.3 \mu \mathrm{mol} \mathrm{m}^{-2} \mathrm{~s}^{-1}$ $(+0.8 \%)$ and $1.9 \mu \mathrm{mol} \mathrm{m}{ }^{-2} \mathrm{~s}^{-1}(-0.1 \%)$ and the RMSE is $11.4 \mu \mathrm{mol} \mathrm{m} \mathrm{s}^{-2} \mathrm{~s}^{-1}(0.9 \%)$ and $4.0 \mu \mathrm{mol} \mathrm{m} \mathrm{m}^{-2} \mathrm{~s}^{-1}(0.3 \%)$. The correlation coefficient is greater than 0.99 . It is also shown that the proposed technique provides better results than two state-of-the-art empirical methods estimating the global PPFD from the global irradiance (Jacovides et al., 2004; Udo and Aro, 1999).

The proposed technique is very useful for the operational estimation of PAR when computational load and great accuracy in PAR are major issues. In addition, this technique may be extended to be able to accurately estimate other spectral quantities taking into account spectral absorption of photosynthetic pigments found in plants and algae such as chlorophyll, carotenoids. The authors are aware of the heuristic way used for selecting the specific NBs for each KB in their work. Other ways are possible. For example, one may think of using the variance between $\mathrm{KT}_{\mathrm{KB}}$ and all $\mathrm{KT}_{i}$ within a given $\mathrm{KB}$ to determine automatically the need for more than one sub-interval. The greater the number of sub-intervals, the higher the accuracy in PAR computation at the expense of a greater number of affine functions.

Acknowledgements. The research leading to these results has received funding from the ADEME, research grant No. $1105 \mathrm{C} 0028$.

Edited by: S.-E. Gryning

Reviewed by: two anonymous referees

\section{References}

Gueymard, C.: The sun's total and the spectral irradiance for solar energy applications and solar radiations models, Solar Energy, 76, 423-452, 2004.

Jacovides, C. P., Timvios, F. S., Papaioannou, G., Asimakopoulos, D. N., and Theofilou, C. M.: Ratio of PAR to broadband solar radiation measured in Cyprus, Agr. Forest. Meteorol., 121, 135140, 2004.

Kato, S., Ackerman, T., Mather, J., and Clothiaux, E.: The $k$ distribution method and correlated- $k$ approximation for shortwave radiative transfer model, J. Quant. Spectrosc. Ra., 62, 109121, 1999.

Lefèvre, M., Oumbe, A., Blanc, P., Espinar, B., Gschwind, B., Qu, Z., Wald, L., Schroedter-Homscheidt, M., Hoyer-Klick, C., Arola, A., Benedetti, A., Kaiser, J. W., and Morcrette, J.-J.: McClear: a new model estimating downwelling solar radiation at ground level in clear-sky conditions, Atmos. Meas. Tech., 6, 2403-2418, doi:10.5194/amt-6-2403-2013, 2013.

Mayer, B. and Kylling, A.: Technical note: The libRadtran software package for radiative transfer calculations - description and examples of use, Atmos. Chem. Phys., 5, 1855-1877, doi:10.5194/acp-5-1855-2005, 2005.

McCree, K. J.: Test of current definitions of photosynthetically active radiation against leaf photosynthesis data, Agric. Meteorol., 10, 443-453, 1972.

Oumbe, A., Blanc, P., Gschwind, B., Lefevre, M., Qu, Z., Schroedter-Homscheidt, M., and Wald, L.: Solar irradiance in clear atmosphere: study of parameterisations of change with altitude, Adv. Sci. Res., 6, 199-203, doi:10.5194/ASR-6-199-2011, 2011. 
Udo, S. O. and Aro, T. O.: Global PAR related to global solar radiation for central Nigeria, Agr. Forest. Meteorol, 97, 21-31, 1999.
Wandji Nyamsi, W., Espinar, B., Blanc, P., and Wald, L.: How close to detailed spectral calculations is the $k$-distribution method and correlated- $k$ approximation of Kato et al. (1999) in each spectral interval?, Meteorol. Z., 23, 547-556, doi:10.1127/metz/2014/0607, 2014. 